\title{
LABVIEW SOFTWARE-BASED BUILDING SUPERVISING AND EVENTS MONITOR SYSTEM FOR NET ZERO-ENERGY STRATEGIES IMPLEMENTATION
}

\author{
Dr. Csaba SZÁSZ \\ Department of Electrical Machines and Drives \\ Faculty of Electrical Engineering, Technical University of \\ Cluj \\ Cluj, Romania \\ Csaba.Szasz@emd.utcluj.ro
}

\author{
Dr. Géza HUSI \\ Electrical Engineering and Mechatronics Department \\ University of Debrecen, Faculty of Engineering \\ Debrecen, Hungary \\ husigeza@eng.unideb.hu
}

\begin{abstract}
As it is well known, due to the continuously decreasing trend of the alternative energy technologies and the costs of the traditional fossil fuels increase, the development of resident or commercial buildings with greatly reduced energy needs becomes a high ranked and more pressing scientific challenge. In topic with this technological and scientific provocation, the paper presents a LabView software-based building supervising and events monitor system designed and developed with the basic purpose to serve as support for net zeroenergy control strategies implementation in intelligent buildings. There after a briefly presentation of the adopted intelligent building development strategy, the net zero-energy concept is presented and discussed. Once these theoretical aspects have been expressed and clarified, a multi-layer type implementation is unfolded, where the background layer it is a building supervising and events monitor system. The main software development steps of this system are detailed presented to prove the feasibility and reliability of the adopted implementation strategy.
\end{abstract}

Keywords - supervising system, intelligent building, net zeroenergy, HVAC system, event monitoring

\section{INTRODUCTION}

In international references a net zero-energy building (NZEB) is defined as a resident or commercial building with greatly reduced energy needs through efficiency gains such that the balance of energy needs can be supplied with renewable technologies [1]. According to this general term definition, the essence of the concept is that by using low-cost and locally available nonpolluting sources they generates energy onside, in a quantity equal or greater than the total amount of energy consumed onside in the building. By using integrated design and building technologies, designer engineers are able to determine which energy efficiency strategies and what type of renewable on-site generation will contribute to higher energy performance to meets the requirements of the residential or commercial building considered. Therefore, it can be clearly established what kind of design and development strategies must be adopted in order to ensure an adequate energy balance, and as a result, comfortable and healthy home or workplace it is possible to be created, with general characteristics that make NZEB buildings desirable and financially rewarding as well.

However, it is no doubt among scientist focused on this research area that nowadays the net zero-energy goal becomes more practical and has been emerged among the most important research tasks of the engineering community. Therefore, not only the progress made in the new renewable technologies makes possible a rapid advancement in this scientific area, but it is highly improved by academic research as well. As a result of these efforts, in the last decade a high amount of leading-edge case studies have been published in international journals to demonstrate the progress toward achieving net zero-energy goal in concrete examples [2, 3, 4]. Without entering in detailed theoretical approaches, it is mentioned here that according to reference [1], four commonly used definitions are discussed in the international references: net zero site energy, net zero source energy, net zero energy costs, and net zero energy emissions. This classification it is mentioned just to outline that the zeroenergy concept allows for a wide range of approaches due to many options for producing and conserving energy combined with the many ways of measuring energy.

Additionally a particular difference is made in usage between North America and Europe regarding the ZEB concept and its definition. However, here the commercial and residential buildings that uses nonpolluting sources they generates energy onside, embedding complex heating, ventilation and air conditioning systems (HVAC), supervising and event monitor systems, or other complex automation 
systems that operates together to achieve the above mentioned NZEB goal, will be referred in a short way as "intelligent buildings". Obviously, the main goal of this paper is not to unfold the theoretical considerations regarding the above referred theoretical concepts, but rather to introduce our design and development strategies regarding the intelligent buildings implementation that are capable to reach as much possible the mentioned NZEB goal.

\section{INTELLIGENT BUILDING MULTI-LAYER IMPLEMENTATION STRATEGY}

Considering the immense complexity of the undertaken tasks of designing and implementing a complete building automation system suitable to cover all the requirements briefly mentioned under the "intelligent building" concept, by following a net zero-energy control strategies implementation, a well established development schedule is required.

For this reason, a specially conceived multi-layer implementation strategy covering all the research steps required for intelligent buildings experimenting is introduced and unfolded, as shown below in figure 1 .

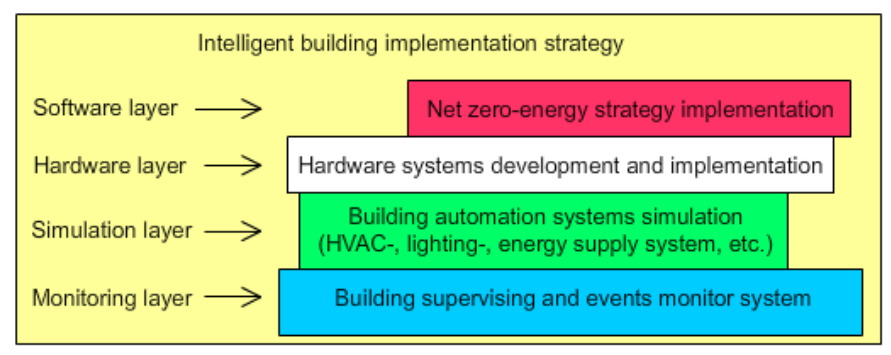

Fig. 1. Intelligent building multi-layer implementation strategy

The essence of this partition lies mainly on practical development considerations. It is no doubt that in each particular case - mostly in the first step of the developments it is required the detailed knowledge of the architectural features and particularities of the residential or commercial building being considered for experiment. Such kind of features refers to the exact number of building rooms, their location, the spacing's distribution and sizes, number of floors, annex buildings, existing basements or other architectural elements. At the same time, it is important to mapping and count the total number of doors and windows and their physical arrangement. Furthermore, it is necessary to know the exact placement of all the lighting sources in the building, the location and number of heating elements, fan coils, or airconditioning elements. Only possessing all this information can be established a real overview about what kind of events can be happen and must be monitored in the building, or the processes amount which are necessary to be supervised. After carefully evaluating all these, it can be succeeded the necessary simulation efforts to acquire the basic knowledge about how the subcomponents of the building automation system operates (HVAC systems, lighting system, grid energy supply system, etc.).

These research efforts usually refer to the followings: what are the parameters evolutions ranges, it limitations, their evolution in the time domain, the dynamics of the systems, their faulttolerance, control strategies required, dynamic response, static and parameters monitoring, etc.

A high level expertise regarding the real-time simulation of the intelligent building all automation subsystems building is a very good background and stable starting point as well to choose the adequate hardware modules, physical components, sensors, data acquisition systems, or digital processing units to start the hardware layer implementation. Of course, only after all the required hardware systems are interfaced and tested properly for operations can follow the software development stage.

This last layer embeds the driver programs development, data acquisition and measurement systems programming, communication busses establishing, user-interface toolkits development, control strategies software implementation, data storage and processing, user friendly facilities development (internet communication, phone commands), monitoring and supervising systems programming, etc. As it can be deduced, a huge number of task and engineering activities must be performed to develop and implement such complex building automation systems. Therefore, this paper it is focused only to introduce and discuss the first research and development level partitioned in figure 1 .

\section{LABVIEW SOFTWARE-BASED SUPERVISING AND EVENT MONITOR SYSTEM DEVELOPMENT AND IMPLEMENTATION}

In accordance with the adopted development strategy, the first layer implementation requires the input information regarding the architectural features and specifics of the building considered for experiment. For this reason a LabView software-based supervising and event monitor system has been designed, of which's input information is considered the building's cadastral plan in a .jpeg or .bmp file format. This plan indicates all the building rooms, the sizes of these, annex buildings, existing basements, the number of doors and windows, or other important particularities. The program fixes this file on the design desktop of the LabView toolkit and places it as a background element. At the same time, it is also necessary to indicate the lighting elements placement, the fan coils or other heating elements arrangement in the building. If this information is available, the designer marks all them on the desktop as shown in figure 2. Here an arbitrary chosen building plan is indicated, free downloaded from the www.schwabinvest.hu internet page. 


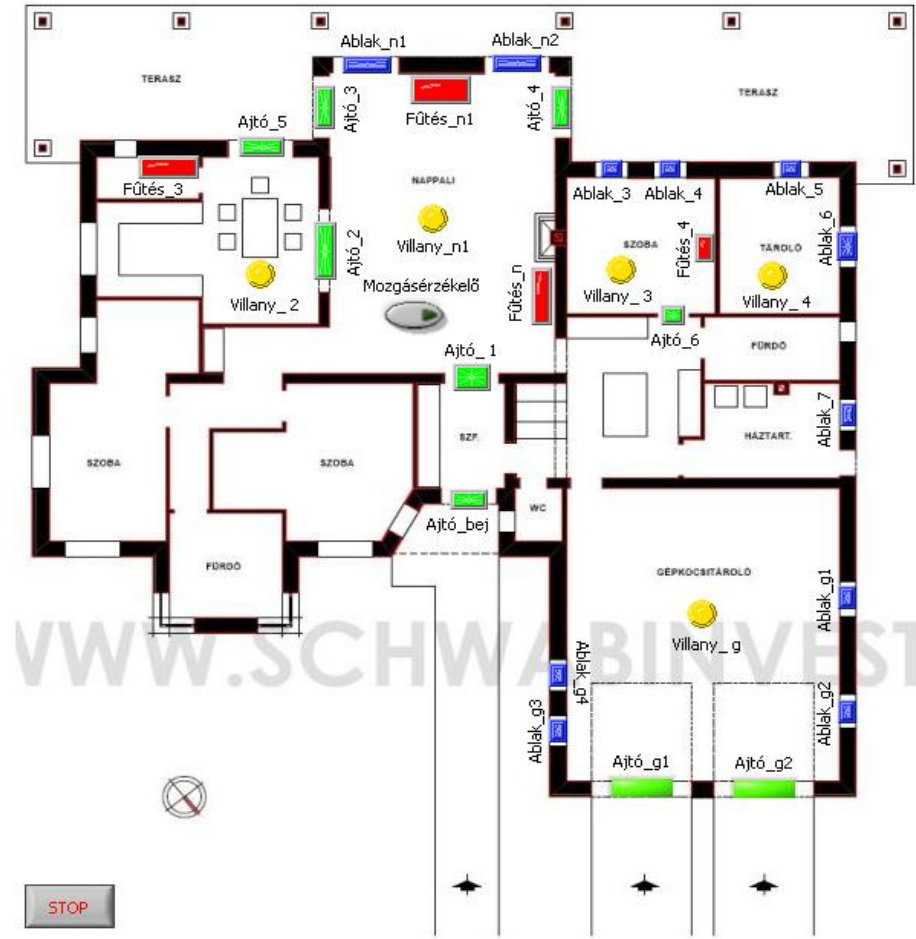

Fig. 2. The arrangement of the LabView graphical elements on the design surface

The graphical elements placed on the desktop surface are arranged after the following rule:

- $\quad$ the doors are marked with green squares;

- the windows are marked with blue squares;

- $\quad$ the lighting elements are yellow circles;

- the motion sensors are marked with gray oval circles;

- the fan coils and heating elements are marked with red squares.

In the considered building are also placed motion detection sensors, therefore if there are no persons in the building (or at nighttime) the entrance door and all the lighting elements switches off. It is self-understanding that the sensors can be programmed for arbitrary timing intervals and the garage doors closes automatically as well. The program supervises all the doors and windows status (open or closed), the lighting system of the building, and the state of the heating elements (turn off/turn on). This monitoring system can be arbitrary linked with the alarm system of the building. In the given example the alarm system operates only if all the windows of the building are closed, otherwise turns off and indicates this state. Of course, according to the customer needs, the building alarm system could be operated after any other programmed logic required.

In the front panel of the LabView software-based development system the state of the doors, windows, lighting elements, fan coils or heating elements are indicate by twostate (logical 0/1) switches, as is presented in figure 3 .

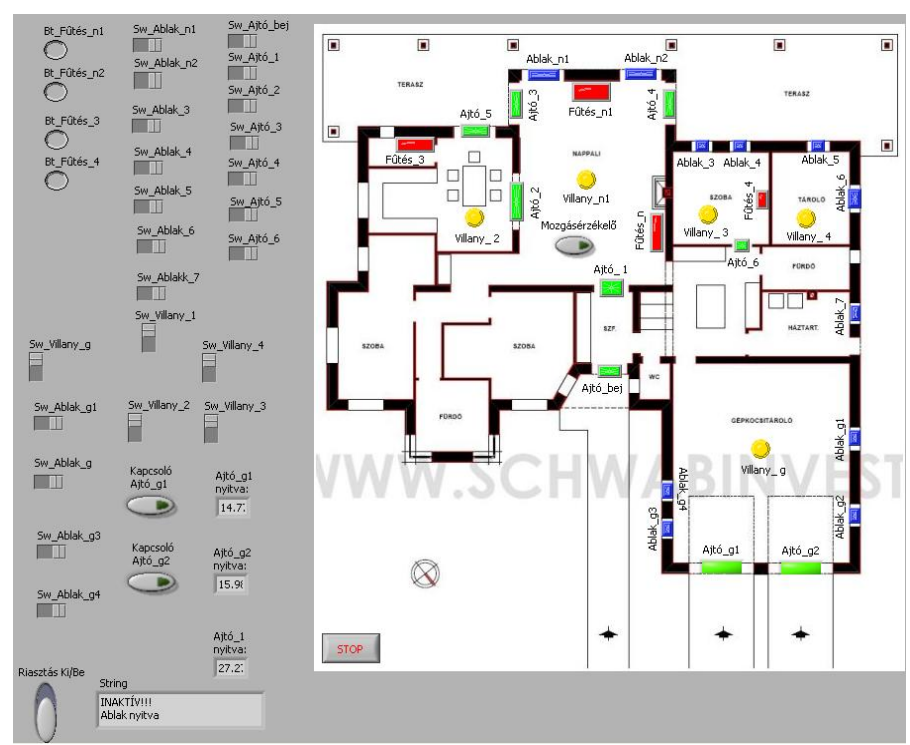

Fig. 3. The front panel of the implemented LabView program

A part of the block diagram resulting from the implemented building supervising and monitor system is shown in figure 4 . The developed program is well suitable for a wide range of settings, modifications, of configurations, in accordance with customer needs and wishes. The only one limitation is linked with the complexity of the given building plan. In case of a very complex buildings (high-rise buildings, a big number of rooms, etc.) the cadastral plane and all the sensors and switches must to fit into the LabView environment's design desktop.

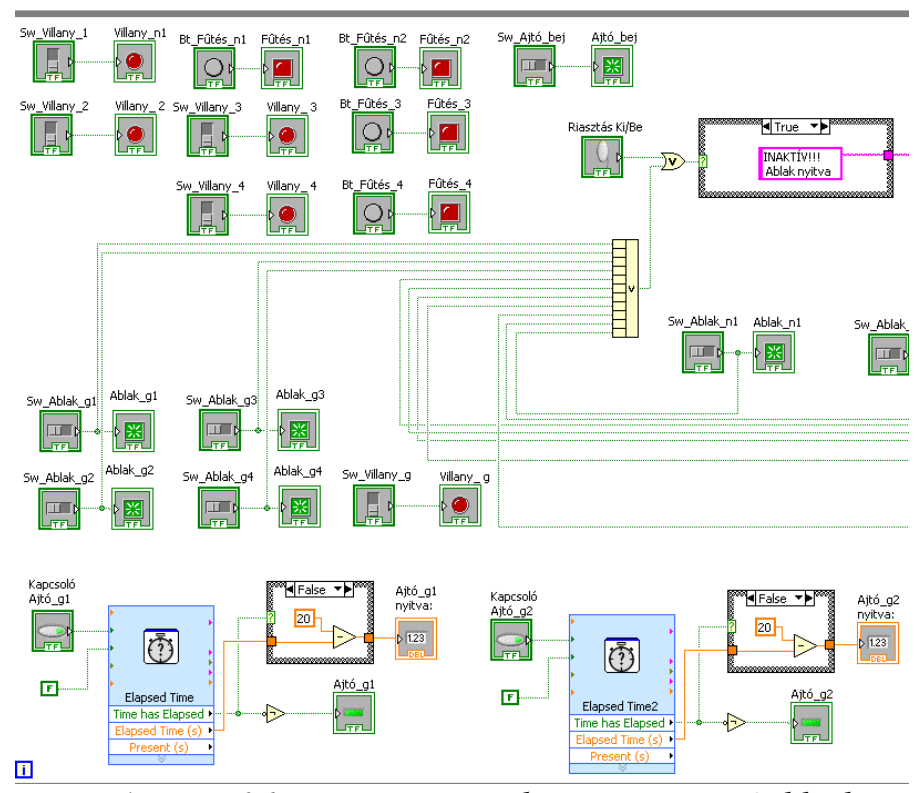

Fig. 4. Part of the supervising and monitor system's block diagram

Future developments of this project requires a FPGA processor-based hardware system to upload the supervising 
and event monitor program, ant to test it in real operating conditions. Then gradually the next development layers given in figure 1 are proposed for implementation.

\section{CONCLUSIONS}

The paper presents a LabView software-based building supervising and events monitor system designed and developed with the basic purpose to support a net zero-energy control strategy implementation in intelligent buildings. Being only the first stage from a multi-layer development project, it has been designed as a flexible and versatile software framework to handle arbitrarily occurring or time-scheduled events monitoring, or supervising tasks as well. The test operations of this graphical oriented program show that it is well feasible for the above mentioned purposes, representing an efficient real-time operating program with user-friendly interface. At the same time it remarks with an immense flexibility, it is easy-to-use, and allows rapid configuration facilities. These abilities recommend to be used as a general framework for a wide range of residential or commercial building applications, without any major changes in its structure or additional reprogramming efforts. By using the given results, the energetics simulation can be realized without operating the building. Based on the simulation system, the regulation system can be regulated, can be made unique.

\section{ACKNOWLEDGEMENT}

The work/publication is supported by the TÁMOP-4.2.2.A11/1/KONV-2012-0041 project.

The project is co-financed by the European Union and the European Social Fund.

\section{REFERENCES}

[1] P. Torcellini, S. Pless, M. Deru, D. Crawley (2006). "Zero Energy Buildings: A Critical look at the Definition" ACEEE Summer Study, Pacific Grove, California, NREL/CP-550-39833

[2] C. Barley, M. Deru, S. Pless, P. Torcellini (2005). "Procedure for Measuring and Reporting Commercial Building Energy Performance" Technical Report NREL/TP-550-38601, Golden CO: National Renewable Energy Lab. www.nrel.gov/docs/fy06osti/38601.pdf

[3] M. Deru and P. Torcellini (2004). "Improving Sustainability of Buildings through a Performance-based Design Approach" Preprint NREL Report No CP-550-36276, World Renewable Energy Congress VIII, Denver, CO: www.nrel.gov/docs/fy04osti/36276.pdf

[4] M. Deru and P. Torcellini (2006). "Improving Sustainability of Buildings through a Performance-based Design Approach" Technical Report NREL/TP-550-38617, Golden CO: National Renewable Energy Lab. www.nrel.gov/docs/fy04osti/38617.pdf . 